\title{
Women's Use Of Indigenous Knowledge Systems To Cope With Climate Change
}

\author{
Angeline Sithole \\ Midlands State University \\ Department of Local Governance Studies, Zimbabwe \\ Mogopodi Lekorwe \\ University of Botswana \\ Department of Political and Administrative Studies, Botswana.
}

\begin{abstract}
This research seeks to ascertain the indigenous knowledge systems that are employed to address the impact of climate change, to examine the effectiveness of these coping strategies, and to suggest possible ways of ensuring sustainability of the strategies employed. There are global climate change policies and mechanisms which serve to guide on ways in which climate change should be considered, they include the United Nations Framework Convention on Climate Change, the Kyoto Protocol, the IPCC 2007 Fourth Assessment Report on Climate Change Impacts, Adaptations and Vulnerability and the Stern Review on the economies of climate change -2006. Indigenous knowledge systems (IKS) are highlighted with the history of these IKS being outlined thereafter the different uses of IKS in various countries are addressed. This desk top research therefore reveals reasons why women should be entrusted with the IKS. The major issue being that women are the ones who labour in the fields and constitute $80 \%$ of the agricultural work force and contribute $50 \%-80 \%$ of the work in the fields. They are the ones who are suitably equipped with the various strategies of coping with climate change and predicting the weather so as to ensure food security for their families. Women, however, face challenges in the use of the IKS, chief amongst these challenges is the patriarchal tradition which does not allow them to contribute in decision making.
\end{abstract}

Keywords: Climate; indigenous knowledge systems; women

\section{INTRODUCTION}

Climate change has been experienced globally and its impact has led to untold suffering in the lives of people. In order to cope and counter the adverse effects of climate change, community members have had to adapt through the use of indigenous knowledge which enables them to ensure food security and survival despite the changes in climate and weather patterns. Climate change is defined as a long term change in the statistical distribution of weather patterns resulting from human activity and from natural climate variability, its impacts are measured and observed at various spatial scales from a local level to a global level and are a threat to global environmental sustainability particularly with associated risks to indigenous communities and their forms of livelihoods, Manyanhaire and Chitura [2015]. Climate change occurs over the long term (decades or longer) and the global warming that has been experienced globally over the past century is a characteristic of climate change. The Intergovernmental Panel on Climate Change (IPCC) Fourth Assessment Report that was published in early 2007 confirmed that global climate change is a fact and it is happening as evidenced by the weather patterns that are being experienced. The same report established that communities that live in marginal lands and that depend on natural resources for their basic survival are among the most vulnerable to the impacts of climate change. 
While one looks at climate change in general, it is important to consider climate variability as it has been experienced globally. Climate variability is defined by Climate Kelpie [2017] as shorter term (daily, seasonal, annual, inter annual, and several years) changes in climate, the well-known drivers which are El Niño and La Niña events. These two phenomena occur as a result of shifts of the warm tropical currents that are found in the Pacific Ocean. This desktop research will address the various policies and mechanisms pertaining to climate change and thereafter the issues of food security are discussed. Indigenous knowledge systems are defined and the history of indigenous knowledge systems is highlighted, together with the ways in which community members in various African countries use IKS. Women play a major role in agriculture, therefore, their role in the use of IKS is explored. Women face a number of challenges in the use of IKS, these challenges are highlighted and finally the conclusions and recommendations wind up the discussion.

\section{GLOBAL CLIMATE CHANGE POLICIES AND MECHANISMS}

The Governments in the world are aware of the risks that are posed by climate change. They have formulated, ratified and adopted a number of policies that can limit or reduce the magnitude that climate change has on the livelihoods of people. The policies are also intended to assist with adaptation to the impact of climate change. The policies are discussed below: United Nations Framework Convention on Climate Change (UNFCC) - article 4 of the framework calls upon developed countries which are parties to the Convention to consider the needs and challenges that developing countries which are also party to the Convention are facing with regard to the adverse effects that arise from climate change. Developed countries are urged to support social groups living in these countries with the transfer of knowledge and technology in order to strengthen their resilience to the adverse effects of climate change on their livelihoods, Macchi et al [2008].

Kyoto Protocol- the Kyoto Protocol came about as a result of the United Nations Framework Convention on Climate Change. According to Article 10 of the Kyoto Protocol all countries globally should develop national and/or regional programmes to both limit Green House Gas emissions and improve the quality of Green House Gas data via consistent methods.

IPCC 2007 Fourth Assessment Report on Climate Change Impacts, Adaptations and Vulnerability -this Report is composed of three parts which are structured as follows: The first part gives an overview about observed impacts of climate change on the natural and human environment and about new assessment methods and the characterization of future conditions. Part II addresses current knowledge about future impacts of climate change on a global scale and across the regions. Part III provides information about current knowledge on responding to climate change.

Stern Review on the economies of climate change -2006- this review assesses the economic impacts of climate change as well as the cost of mitigating climate change. This review demonstrates that the costs of climate change are inequitably borne by developing countries as a result of their geographic exposure, low incomes and greater reliance on climate sensitive factors such as agriculture. Several chapters in the review address the implications of climate change for traditional and indigenous communities, Macchi et al [2008].

\section{FOOD SECURITY}

Food security was defined at the World Food Summit in 1996 as a situation that exists when all people, at all times have physical, social and economic access to sufficient, safe and nutritious food which meets their dietary needs and food preferences for an active and healthy life. 
According to the Food and Agriculture Organisation (FAO) [1983], the ultimate objective of world food security should be to ensure that all people at all times have both physical and economic access to the basic food they need. Food security should have three aims namely: ensuring production of adequate food supplies, maximizing stability in the flow of supplies, and securing access to available supplies on the part of those who need them. It is important to highlight the issue of food insecurity which is the opposite of food security. There are two general types of food insecurity which are chronic food insecurity (this is long term or persistent) and transitory food insecurity (short term and temporary). The aspect of seasonal food insecurity can then be considered here as it can be said to fall between chronic and transitory food insecurity. It is predictable and follows a sequence of known events, therefore, can be said to be similar to chronic food insecurity. Since seasonal food insecurity is of limited duration as it occurs when there is a cyclical pattern of inadequate availability and access to food, therefore, it can be said to be transitory food insecurity. Seasonal insecurity occurs when there are seasonal fluctuations in the climate, cropping patterns, work opportunities and diseases, FAO [2008]. It is important to address issues pertaining to food security because the Zimbabwean government has as one of its goals the attainment of Sustainable Development Goal 2-zero hunger. Failure to curb the lack of or inadequate food within the country would lead to the life expectancy being reduced in the long run.

\section{BACKGROUND INFORMATION ON INDIGENOUS KNOWLEDGE SYSTEMS}

The knowledge of indigenous knowledge systems is said to be as old as humankind itself for as long as there have been people living on earth, indigenous knowledge has been applied. When the Europeans colonized countries they focused on the animals and plants that are useful but which are unknown to European science. Mafongoya and Ajayi [2017] say that the scientists did not limit their reliance on local experts to the simple identification of species of interest; they also adopted from the local people the entire classification systems that interpreted ecological systems according to indigenous logic. This indigenous knowledge was then transferred to western taxonomic knowledge and practices and used by the Europeans themselves. Therefore, western scientific understanding expanded the appropriation of traditional ecological knowledge but without acknowledging the natives whose discoveries they had borrowed from the countries that they had colonized.

The attitudes of the western scientists were altered in the mid-20 $0^{\text {th }}$ century by Conklin in the Philippines in 1954 with the Hamunoo community. This challenged and raised questions about the so called superior intellect and training of scientists by demonstrating the complexity, accuracy and detail of indigenous knowledge and its value to the scientific community. According to Mafongoya and Ajayi [2017], it is unfortunate that indigenous knowledge is regarded as being backward, static and a hurdle to modernization, it has also been viewed as being part of a residual, traditional way of life. Mafongoya and Ajayi [2017] further argue that it is linked to low prestige rural life such that even those who know this type of information may even believe it to be inferior to scientific knowledge. This view is unfortunate because these indigenous knowledge systems have enabled people to live in harmony with nature for hundreds of years because it is central to sustainable development.

\section{INDIGENOUS KNOWLEDGE SYSTEMS}

Bhebe and Sithole [2014] state that the significance of indigenous knowledge systems is that they form the basis through which communities express themselves, this is often marked in extreme weather conditions where communities are forced to develop strategies to cope with stresses for which there may be little assistance through the formal structures. Communities have relied on indigenous knowledge systems by using some animals, plants, birds and insects to predict the weather. In addition to this, they have used the moon and the sun, the direction 
and strength of the wind, movements and positions of clouds as well as the positions of the stars, even shadows associated with the sun. This has been used to ensure that the crops that are planted will be successfully harvested. Manyanhaire and Chitura [2015] argue that such knowledge is used in determining timing of important agricultural activities and predicting disasters before they happen.

Indigenous knowledge (systems) is referred to as community, local, traditional (ecological) knowledge. It is possessed by the local communities of respective areas and having such indigenous information can play a very important role in enabling communities to adapt to climate change and variability, Mafongoya and Ajayi [2017]. This kind of knowledge is transmitted orally through songs or folk tales, it can also be conveyed through observations and actions or through demonstrations, from one generation to another and it is renewed through the generations to enable food security, environmental conservation and management, ditto. Indigenous knowledge is not focused on one subject only but it addresses a number of issues such as, agriculture, education, and natural resources management etc, Ngenwi et al [2011].

Once communities are in a position to develop indigenous knowledge and use it as a bulwark in times of need it enhances their resilience and adaptation to climate variability and climate change. These skills, knowhow, practices and representations guide societies in their innumerable interactions with their natural surroundings; this knowledge is passed between generations in a traditional context and forms part of the lifestyle of indigenous and local communities. And because people have lived in harmony with nature for centuries, over the years they have obtained vital knowledge about the environment in which they live. As it has been stated before, these communities have acquired intimate knowledge on a wide array of topics ranging from environmental, biophysical, economic and social issues to spiritual knowledge, Ngenwi et al [2011]. This, therefore, explains the reason why such indigenous knowledge is sometimes referred to as 'traditional knowledge systems'.

Mafongoya and Ajayi [2017] say that indigenous knowledge systems are social capital for the poor (especially the vulnerable rural women) whose main asset is to ensure survival, produce food and secure livelihoods. It is unfortunate that such indigenous knowledge systems lose their value in society and are not relied upon because of the onset of foreign teachings and development, Mafongoya and Ajayi [2017]. The communities now appear to prefer relying on the scientific knowledge that they obtain from foreigners rather than use the information that has been handed down to them by their forefathers. This information on indigenous knowledge systems is not documented by the communities it is therefore lost by not passing it down the generations, once the skills are lost they cannot be recovered. Burman [2016] states that indigenous people (especially rural women) are the most affected by climate change therefore it is important that attention be focused on indigenous knowledge as a component of climate change adaptation strategies.

\section{DIFFERENT USES OF INDIGENOUS KNOWLEDGE SYSTEMS}

Indigenous knowledge systems are used throughout the world and in some cases may be unique to the country in which the community members are residing. Community members rely on this knowledge as they are in a better position to predict weather patterns. Gebremikael [2016] says that traditional weather forecasting is an affordable, accessible, and actionable source of weather and climate information, the Afar pastoralists of north eastern Ethiopia observe biophysical entities such as the stars, winds, livestock, insects, birds, trees etc to predict weather and climate. Svotwa et al [2007] say that communities in the eastern region of Zimbabwe have predicted the weather by basing on their experiences on changes in wind 
flow patterns and directions as well as the behavior of animal and plant species. In Burkina Faso elderly male farmers formulate hypotheses about seasonal rainfall by observing natural phenomena, while cultural and ritual specialists draw predictions from divinations, visions or dreams, Roncoli et al [2001]. They also use indicators such as the timing, duration and intensity of cold temperatures during the early part of the dry season, timing or fruiting by certain local trees, the water level in streams and ponds, the nesting behavior of certain birds and insect behavior in rubbish heaps outside compound walls. This has enabled them to predict the weather or map out ways of surviving natural disasters such as drought or floods. The communities of Swaziland use the height of the nest of the emahlokohloko bird (ploceus spp) to predict floods, if this bird's nest is high up the trees by the river bank it implies that there will be flooding but if the nests are hanging low it implies that the floods are highly unlikely. Furthermore, other Swazis use the cry of certain birds to predict rain and yields of certain wild fruits to predict famine, Musa and Omokore [2011]. The Swazis also use wind direction, the shape of the crescent moon and the behavior of certain animals to predict changes in the weather, ditto.

Zimbabweans use wild fruits and animals to predict the weather in the same way as the Swazis, the disappearance and delayed fruiting of trees such as tsambatsi (lannea edulis), maroro(annona senegalensis) and hute (syzygium cordatum) as well as the profuse fruiting of the muhacha (parinari curatellifolia) tree including the delayed regrowth of grasses from August to October are an indication that drought is imminent, Mapfumo et al [2015] in Jiri et al [2016]. A research conducted in the southern part of Zimbabwe revealed that the communities rely on wild fruit trees umtshwankela (vitex Mombasa), umkhuna (parinari curatellifolia), umthunduluka (ximenia caffra) as a sign of the coming rainy season, an abundance of these wild fruits towards the rain season indicates that below normal rainfall will be experienced, Ndiweni and Ndlovu [2013]. Community members not only rely on plants but have been said to use birds in weather forecasting. Mapara [2009] is of the view that the sound of insingizi (bucorvus leadbeateri) and inkanku (clamator jacobinus) would mean the rains will fall in few hours time. If chickens feed while it is drizzling it implies that it will drizzle for 2-3 days.

Ngenwi et al [2011] found the following adaptation strategies when they conducted their research in Cameroon. There is storage of extra harvest for food supply separately from that destined for the market. As well as planting materials for the coming planting season stored separate from food reserves. Ngenwi et al [2011] commend these strategies and suggest that the storage of food for use during drought or dry seasons could be strengthened through training and provision of community storage facilities. That way the community members are trained on various aspects for example on the adoption of the use of local plant materials in protecting grains from weevils in storage. Crop diversification is also practiced; this is a practice where many crop species are planted on the same piece of land to guard against crop failure in times of adverse climatic conditions. According to Musa and Omokore [2011] Nigerian community members have devised methods of dealing with climate change and diversity by growing drought resistant and early maturing indigenous crop varieties, gathering wild fruits and vegetables, wetlands cultivation, livestock diversification and splitting. This has enabled them to survive the natural hazards that occur.

However it is important to note that no single prediction is accepted at face value. Gebremikael [2016] suggests that triangulation is vital so as to make the safest livelihoods decisions. This is because weather forecasting is a dynamic process where information is collected by traditional observations and predictions. This information is then triangulated with different sources including the formal weather forecasting systems, this serves to ensure that not only the most probable forecasting is used for decision making but also that 
forecasting techniques that lose their reliability are excluded, Gebremikael [2016]. Use of indigenous knowledge systems is important for adapting effectively to climate change at community level and can be combined with formal weather forecasting systems for more effectiveness.

\section{IMPORTANCE OF WOMEN IN THE USE OF INDIGENOUS KNOWLEDGE}

The Sustainable Development Goal 2 calls upon ending of hunger therefore it is stated 'Zero Hunger' and the ZimAsset Cluster 1 is focused on food security and nutrition. In line with these goals women play a major role in agriculture not only in Zimbabwe but throughout the world, they constitute the backbone of agriculture because they contribute $50 \%-80 \%$ of the work in the fields. Denton [2002] states that women make up $80 \%$ of the agricultural work force, a research by Acharya and Bennet [1983] in Grantham [1996] revealed that Nepalese men take responsibility for land preparation, ploughing and harvesting. The men are tasked with these activities while the Nepalese women are tasked with collection of fodder, feeding the livestock, kitchen gardening, collection of organic fertilizer and manure, and fertilizing of crops. Nepalese women are also involved in farm maintenance, seed bed preparation, sowing, planting and weeding, seed selection, threshing, food processing and water collection. In their research Olatokun and Ayanbode [2008] argue that rural women are pivotal to development in African countries because they play a diversified role in development. They contribute to the family and wage activities, engage in marketing and the distribution of food stuff and as wives and mothers ensure the survival of the family and collectively, the society. Their domestic activities vitally contribute to the maintenance of the local economy to ensure sustainable development. For many centuries women have been charged with ensuring that their families are secure in terms of food security they have achieved this by using the indigenous knowledge systems (special/traditional knowledge) that has been orally handed down through the generations. Women are increasingly vulnerable to climate variability and change especially if they rely on rain fed farming therefore knowledge and use of indigenous knowledge systems will enable them to cope.

Women are able to keep record of events and are able to recall past extreme events that had a drastic impact on the community, because they are able to recall important events they should be included in the decision making process within the communities, Ngenwi et al [2011]. Women are valuable contributors to the life and work of the community as they can be community leaders and natural resource managers who devise strategies that can help manage and cope with climate related risks. In addition to this, women have a strong body of knowledge and expertise that can be used in climate change mitigation, disaster reduction and adaptation strategies, Ngenwi et al [2011]. This makes women be at the centre of sustainable development through the use of indigenous knowledge systems.

Rural women are exposed to the difficulties of taking care of their families while relying on rain fed crops to sustain the family, unfortunately, the poor social conditions they are exposed to which are exacerbated by climate change place them in the category living below the threshold of poverty-70\% of the 1.3 billion people in the developing world, Ngenwi et al [2011]. Therefore, rural women who are regarded as custodians of this type of knowledge have been seen to be useful in the enhancement of sustainable development through the use of indigenous knowledge. The importance of indigenous knowledge is that it can be transferred and adapted to other communities that are in similar situations, it encourages community participation and empowers community members, and it can provide invaluable information about the local context, Dube and Munsaka [2018]. 
Once women possess indigenous knowledge systems they are in a better position to take care of themselves and deal with the impacts of climate change with little or no external assistance. This is because they use their indigenous knowledge as a planning tool.

\section{CHALLENGES FACED IN THE USE OF INDIGENOUS KNOWLEDGE SYSTEMS}

According to Ngenwi et al [2011] the following are some of the challenges that are faced by rural women as they try to use indigenous knowledge systems as a coping strategy.

There is limited access to resources, policies that are formulated at national level are divorced from what is happening on the ground, within the communities they encounter social and cultural barriers, there is lack of information and limited access to information, rural women have limited mobility as compared to men, though migration is a coping strategy that is employed by women, women also have limited roles in decision making because of the patriarchal society, they face loss of traditional rights, and because much time is spent fetching water and firewood they literally have little time for other activities. These issues hinder women as they try to use indigenous knowledge to cope with climate change. In line with the above, Dube and Munsaka [2018] put forward the following challenges that are faced by rural women, this type of knowledge (indigenous knowledge) is not wholly trusted by many in the community and it lacks documentation.

\section{CONCLUSIONS AND RECOMMENDATIONS}

Climate change and climate variability are inevitable, and communities have mapped ways of ensuring survival. It has been seen that communities have developed survival strategies which are referred to as Indigenous Knowledge Systems. These Indigenous Knowledge Systems are knowledge that is passed on orally from one generation to the next. This traditional knowledge is different according to the respective communities. Women are the main producers of the staple foods that communities rely on and they make up more than three quarters of the agricultural workforce as they work in the fields to ensure that their families are well fed and nourished. Those that rely on rain fed agriculture bear the brunt of the effects of climate change and this affects their harvests. Women rely on Indigenous Knowledge Systems to cope with climate change. Unfortunately, they face challenges as they try to ensure their survival. They have limited access to resources, the policies that are formulated at national level are divorced from what is happening on the ground. Women have limited roles in decision making because of the patriarchal society they find themselves in. It is therefore recommended that the differences in social roles and financial situations between men and women be addressed. It is important to appreciate that women's role in society is very important because they are important agents of change, if they are given the chance. Policy makers and community leaders should increase women's involvement in decision making as they are the ones that are tasked with ensuring survival of the community. The governments should make sure that women have increased access to resources to ease the burden that they are faced with. The problems of gender inequality and patriarchy have to be done away with as they hinder women's efforts to enable survival of their families and the community at large.

\section{AUTHORS' BIOGRAPHY}

Angeline Sithole is a lecturer in the Department of Local Governance Studies at the Midlands State University. She is currently studying towards a PhD in Public Administration with the University of Botswana, her area of research is based on Implementation of the Zimbabwe National Gender Policy: A case of local authorities in the Midlands Province. She is interested in issues pertaining to Gender Mainstreaming. 
Professor Mogopodi Lekorwe is a lecturer in the Department of Political and Administration Studies at the University of Botswana

\section{References}

Acharya, M., and Bennet, L. [1983]. Women and the subsistence sector, economic participation and household decision making in Nepal World Bank Staff Working Papers No 526, Washington DC.

Bhebe, Q. and Sithole, A. [2014]. Drought coping strategies at household level: a case of Insiza District ward 9, Zimbabwe. The Dyke A Journal of the Midlands State University. 8[2],119-136.

Burman, A. [2016]. Climate change otherwise: indigenous knowledge and the coloniality of reality. The Indigenous Knowledge and Climate Change Conference. 2-3 November 2016 Marrakesh, Morocco.

Climate Kelpie. [2017]. Climate variability and climate change what is the difference? Available: http://www.climatekelpie.com.au/understand-climate/climate-science/climate-variability-and-climate-changewhats-the-difference [2018, May 3].

Denton, F. [2002]. Climate change vulnerability, impacts and adaptation: why does gender matter? Gender and Development. 10[2], 12-20 https://doi.org/10.1080/13552070215903 [2018, June 5].

Dube, E., \& Munsaka, E. [2018]. The contribution of indigenous knowledge to disaster risk reduction activities in Zimbabwe: A Big Call to Practitioners. Journal of Disaster Risk Studies. 10 [1].

FAO [1983]. World Food Security: A reappraisal of the concepts and approaches. Director General's Report, Rome.

FAO [2008]. An Introduction to the Basic Concepts of Food Insecurity. Available:

http://www.fao.org/docrep/013/al936e/al936e00.pdf [2018, June 25].

Gebremikael, M.B. [2016]. Traditional weather forecasting among Afar pastoralists in north eastern Ethiopia: role in climate change adaptation. The Indigenous Knowledge and Climate Change Conference. 2-3 November 2016 Marrakesh Morocco.

Grantham, K. [1996]. Gender and indigenous knowledge: The role of Nepalese women in agricultural research and development. Available:

https://assets.publishing.service.gov.uk/media/57a08db840f0b649740019e6/R6322Genderandindigenouskno wledge.pdf [2018, May 26].

Jiri, O., Mafongoya, P.L., Mubaya, C., \& Mafongoya, O. [2016]. Seasonal climate prediction and adaptation using indigenous knowledge systems in agriculture systems in Southern Africa: a review. Journal of Agricultural Science. 8[5], 156-172.

Macchi, M., Oviedo, G., Gotheil, S., Cross, K., Boedhihartono, A., Wolfangel, C., \& Howell, M. [2008]. Indigenous and traditional peoples and climate change: Issues Paper.

Mafongoya P.L., \& Ajayi O.C. [2017]. Indigenous Knowledge Systems: Their history, development over time and role in sustainable development and climate change management. In P.L. Mafongoya \& O.C. Ajayi, Eds, Indigenous Knowledge Systems and Climate Change Management in Africa. The Netherlands: CTA.

Mapara, J. [2009]. Indigenous knowledge systems in Zimbabwe: juxtaposing post colonial theory. The Journal of Pan African Studies. 13[1].

Mapfumo, P., Mutambanengwe, F., \& Chikowo, R. [2015]. Building on indigenous knowledge to strengthen the capacity of smallholder farming communities to adapt to climate change and variability in Southern Africa.

Manyanhaire, I.O., \& Chitura, M. [2015]. Integrating indigenous knowledge systems into climate change interpretation: perspectives relevant to Zimbabwe. Greener Journal of Education Research. 5[2], 027-036.

Musa, M.W., \& Omokore, D.F. [2011]. Reducing vulnerability and increasing resiliency to climate change: learning from rural communities. Journal of Agricultural Extension. 15[1].

Ndiweni, N.J., \& Ndlovu, C. [2013]. An exploration of the value of indigenous knowledge adaptation strategies in ensuring food security and livelihoods in Southern Zimbabwe. Global Journal of Human Social Science Geography, Geo Sciences, Environmental Disaster Management. 13[7],50-54.

Ngenwi, A. A., Mafeni, J.M., \& Etchu, K.A. [2011]. Climate change and adaptation strategies: lessons from women's indigenous knowledge practices. Climate Change Symposium Panel 10 Roles of Local and Indigenous Knowledge in Addressing Climate Change.

Olatokun, W.M., \& Ayanbode, O.F. [2008]. Use of indigenous knowledge by rural women in the development of Ogun State Indilinga. African Journal of Indigenous Knowledge Systems. 7[1], 47-63. 
Roncoli, C., Ingram, K., \& Kirshen, P. [2001]. The costs and risks of coping with drought: livelihood impacts and farmers' responses in Burkina Faso. Climate Res. 19:119-132.

Svotwa, E.J., Manyanhaire, I.O., \& Makanyire, I.J. [2007]. Integrating traditional knowledge systems with agriculture and disaster management : a case of Chitora communal lands. Journal of Sustainable Development in Africa. 9[3], 50-63. Available: http://www.jsd-

africa.com/Isda/V9N3_Fall2007/ARC_IntegratingTraditionalKnowSys.pdf [2018, May 31]. 